\title{
MÉXICO OFFSHORE. EL OSCURO PAPEL DE LA MISCELÁ- NEA FISCAL
}

MEXICO OFFSHORE. THE DARK ROLE OF THE FISCAL MISCELLANEOUS

MIRIAM GONZÁLEZ SERRANO ${ }^{1}$

REsumen: En el ámbito fiscal internacional, se busca que los países no compitan en forma desleal a través de regímenes fiscales preferentes o paraísos fiscales que erosionan la base tributaria de los residentes en terceros países. Recientemente, México ha sido cuestionado por su baja tributación y regímenes de beneficio para los extranjeros. Nosotros sostenemos que algunos de estos regímenes están previstos en la Resolución Miscelánea Fiscal, la cual no cuenta con un marco jurídico acabado, ya que no se obliga a sus creadores a realizar análisis económicos y jurídicos previos ni posteriores a su implementación, ni estudios sobre sus repercusiones a nivel internacional. Este inadecuado control regulatorio y financiero, encuadra en los supuestos para calificar al país como una jurisdicción con regímenes fiscales preferentes de acuerdo a los criterios de la OCDE y, en el plano doméstico, implica que no existe rendición de cuentas debida por la autoridad.

Palabras Clave: Regímenes fiscales preferentes, Resolución Miscelánea Fiscal, Transparencia regulatoria, Rendición de cuentas.

Aвstract: In the international tax field, it is sought that countries do not compete unfairly through preferential tax regimes or tax havens that erode the tax base of residents in third countries. Recently, Mexico has been questioned because of its low taxation and benefit regimes for foreigners. We argue that some of these regimes are in the Miscellaneous Fiscal Resolution which does not have a legal framework finished, since

${ }^{1}$ Maestra en Derecho. Docente de la Facultad de Derecho de la Universidad Nacional Autónoma de México; doctoranda por el Instituto de Investigaciones Jurídicas de la misma Universidad. @Miriam53974344, >mgonzalez@derecho.unam.mx> 
its creators are not obliged to perform economics and legal analysis before or after its implementation, nor studies on its repercussions at the international level. This inadequate regulatory and financial control, fits in the assumptions to qualify the country as a jurisdiction with preferential tax regimes according to the OECD criteria and, on the domestic level, it implies that there is no accountability due from the authority.

Keywords: Preferential tax regimes, Miscellaneous Fiscal Resolution, Regulatory transparency, Accountability.

SUMARIO: I. Planteamiento; II. Paraísos fiscales y regímenes fiscales preferentes; III. Resolución Miscelánea Fiscal; IV. REFIPRES. Ley inhibitoria vs RMF permisiva; V. México, offshore para extranjeros; VI. Conclusiones; VII. Fuentes.

\section{PLANTEAMIENTO}

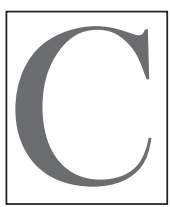

on el término offshore ${ }^{2}$ se identifican entidades o jurisdicciones con regímenes de beneficio fiscal considerados indeseables por constituir una desleal competencia en el ámbito tributario internacional para atraer inversiones o para beneficiar sectores, industrias o grupos en un país determinado. La respuesta internacional hacia estas jurisdicciones o regímenes sugiere el establecimiento de reglas que inhiban la participación de los nacionales en aquellos países, a la vez que se pide a las Naciones no constituir beneficios indebidos para los extranjeros que inviertan en su jurisdicción.

Desde hace algunos años se ha cuestionado si México está compitiendo lealmente en el ámbito fiscal o si es necesario revisar su actuación; así la dirigencia de la Comisión Económica para América Latina y el Caribe

\footnotetext{
${ }^{2}$ El término offshore hace referencia a lo que existe fuera de las costas de cada país y, en el sentido tributario, se refiere a las jurisdicciones, regímenes, entidades o figuras fuera de las fronteras de un país que permiten una tributación menor o nula, en comparación con la que se aplicaría en ese Estado.
} 
(CEPAL) ha hecho notar que la baja recaudación convierte a México en un paraíso fiscal y, en 2019, la Comunidad Europea ha decidido verificar si existen deficiencias en el sistema tributario mexicano. ${ }^{3}$

En este punto, nos preguntamos ¿por qué el país ha sido varias veces descalificado en cuanto a su régimen impositivo si, a primera vista, la imposición sobre la renta tiene una tasa baja pero competitiva y, aparentemente, la Ley del Impuesto sobre la Renta (LISR) no prevé algún régimen preferente? Encontramos entonces que las disposiciones administrativas, particularmente la Resolución Miscelánea Fiscal (RMF), contienen en realidad normas que pueden desaplicar "de facto" los preceptos legales que aparentan un marco normativo competitivo a nivel internacional. Asimismo, advertimos que a través de esas normas se crean beneficios preferentes para ciertos inversores, sin que exista supervisión regulatoria o financiera al respecto.

Así, frente a la idea de que México está cumpliendo normativamente con los requerimientos para tenerlo como un Estado leal en su tributación, surge una nueva interrogante ¿ ¿cuál es el papel de la RMF para la (des)calificación o revisión del país como una jurisdicción con regímenes preferenciales?

Revisando esta problemática, encontramos posturas doctrinarias en torno al alcance que puede tener la RMF, pero esas discusiones se centran en verificar si sus disposiciones transgreden el ámbito de competencia del Poder Legislativo y concluyen con su calificación de inconstitucionales o su validación jurídica a partir de ese parámetro de análisis. Desde otro punto de vista, revisamos el marco jurídico que sostiene la emisión de

\footnotetext{
${ }^{3}$ Crf. Arellano Ramírez, José, ¿Es México un paraíso fiscal?, México, Expansión, 2011, https:/expansion.mx/opinion/2011/02/01/es-mexico-un-paraiso-fiscal-de-facto; European Commission, Questions and answers on the EU list if no-cooperative tax jurisdicions, http://europa.eu/rapid/press-release_MEMO-19-1629_en.pdf.
} 
la RMF y, aunque encontramos disposiciones genéricas, lo cierto es que no localizamos disposiciones normativas que se refieran a la motivación, los objetivos, ni mucho menos los efectos individuales (exenciones, minimización de obligaciones, etc.) y nacionales (recaudatorios y/o presupuestales) de esta RMF, al tiempo que advertimos algunos ejemplos que, "de facto", reducen las obligaciones tributarias de algunos sujetos.

En ese contexto, la tesis que sostenemos es que la RMF juega un papel relevante en sentido negativo para el régimen fiscal mexicano, ya que desaplica las medidas inhibitorias de inversiones y pagos en y para el extranjero en condiciones preferenciales y, además, contiene verdaderos regímenes fiscales preferentes (REFIPRES) que pueden pasar desapercibidos -al comúnpor exceso de tecnicismos, falta de transparencia en sus motivaciones y por la ausencia de análisis previos y post facto sobre sus consecuencias; lo cual además implica que no se estén rindiendo cuentas sobre la administración de los recursos que se comprometen o se renuncian a través de la RMF.

Las siguientes líneas buscarán dar respuesta a la interrogante planteada en torno al papel de la RMF, para demostrar que las circunstancias bajo las cuales se emite esa RMF la convierte en un instrumento para desaplicar las normas fiscales y propiciar la generación de regímenes preferenciales. Conforme a los resultados obtenidos, propondremos algunas medidas para transparentar ese mecanismo administrativo y limitar sus efectos perniciosos.

Para lograr este objetivo, utilizando una metodología deductiva, empírica y analítica, precisaremos algunos conceptos sobre los paraísos fiscales, los regímenes preferentes y la RMF. Respecto de esta última, analizaremos el marco jurídico que sostiene su emisión y revisaremos las posturas que intentan explicar su función normativa. 
En forma relevante, analizaremos las reglas de dicha RMF a partir de 2005, correspondiente a los regímenes fiscales preferentes y, a partir de su análisis, advertiremos los efectos de beneficio "indebido" que tienen sus destinatarios; este parámetro de revisión lo elegimos porque desde 2005 no se modifica sustancialmente la regulación sobre los regímenes fiscales preferentes en el país y, sin embargo, la RMF sí ha tenido cambios que serán motivo de revisión para conocer en qué periodo existieron reglas que permiten una aplicación indebida de la ley fiscal. Por otra parte, para verificar si la RMF contiene beneficios preferenciales para cierto sector de inversionistas extranjeros, revisaremos las reglas de los últimos 5 años, para identificar aquellas que hagan dudar a los demás países de que México compite lealmente con la prohibición de beneficios indebidos; consideramos que 5 años son suficientes para lograr el objetivo planteado, ya que estas reglas no están directamente vinculadas con la inhibición de inversiones y pagos en y para REFIPRES que están vigentes desde 2005. En todo caso, el estudio se centrará en las disposiciones administrativas relativas al impuesto sobre la renta (ISR), por ser la contribución que se analiza para revisar a los REFIPRES.

\section{PARAísos Fiscales Y REGíMENES Fiscales PRE- FERENTES}

Para conocer si un Estado realiza prácticas indeseables de competencia tributaria, se han elaborado una serie de criterios para calificar a un país ya como paraíso fiscal o como una jurisdicción con régimen fiscal preferente. Los criterios que seguiremos son los parámetros creados por la Organización para la Cooperación y el Desarrollo Económicos (OCDE), con independencia de que cada país puede establecer sus propios parámetros de clasificación. 


\section{PARAÍSO FISCAL}

Paraíso fiscal o tax haven es un concepto que, aunque de uso cotidiano, desde el punto de vista jurídico ha ido perdiendo relevancia debido a la forma y los procedimientos que se utilizan para determinar qué país o jurisdicción puede ser calificada jurídicamente como un paraíso fiscal. En un sentido clásico, un paraíso fiscal es un país que impone un ISR mínimo o no tiene dicho impuesto, situación que es aprovechada por las corporaciones para evadir el impuesto que, de otra forma, debiera ser pagado en otra jurisdicción; ${ }^{4}$ estos paraísos no sólo se caracterizan por su baja o nula tributación, sino por la secrecía y anonimato que ofrecen a las empresas como ejes centrales de evasión fiscal. ${ }^{5}$

En 1998, la OCDE emitió uno de los primeros reportes que se ocupan de la competencia tributaria perniciosa. En dicho reporte se listaban los elementos para identificar a un tax haven: a) si la jurisdicción no tiene impuestos o éstos son nominales; b) ausencia de efectivo intercambio de información; c) falta de transparencia y, d) ausencia de requerimientos de actividades sustanciales. ${ }^{6}$ Para 2001, se determina revisar a las jurisdicciones más que como paraísos fiscales, como jurisdicciones no cooperativas en función de las primeras tres condiciones previstas en 1998; hasta la formulación del Plan $\mathrm{BEPS}^{7}$, cuando se da preferencia a revisar la

${ }^{4}$ OCDE, Glossary of tax terms, http://www.oecd.org/ctp/glossaryoftaxterms.html.

${ }^{5}$ European Parliament, Listing of tax haven by the EU, 2018, http://www.europarl. europa.eu/thinktank/en/document.html?reference=EPRS_BRI(2018)621872, p. 2.

${ }^{6}$ OCDE, Harmful Tax Competition: An Emerging Global Issue, París, OECD, 1998, http://dx.doi.org/10.1787/9789264162945-en, p. 22-23.

${ }^{7}$ El Plan de Acción BEPS es un plan para tratar los problemas de la erosión de la base imponible y el traslado de beneficios (BEPS) de un modo coordinado y completo; busca proporcionar instrumentos que alineen mejor la potestad impositiva de cada país con las actividades económicas reales. La observación esencial que alimenta este Plan es la interacción de normas nacionales e internacionales que generan fricciones sin resolver, aprovechadas para evadir el pago de impuestos. Este plan se compone de 
existencia de regímenes fiscales preferentes sobre la base de actividades sustantivas.

\section{RÉGIMEN FISCAL PREFERENTE}

La premisa que utiliza la OCDE para analizar la existencia de un REFIPRE es que se ofrezca alguna forma de "privilegio fiscal en comparación con los principios generales de tributación en un determinado país”, ${ }^{8}$ más no en comparación con otros países; entonces, tales privilegios pueden encontrarse traducidos en la reducción del gravamen, condiciones preferenciales para pagar o reembolsar el tributo o, agregaríamos nosotros, disminución de condiciones que impliquen reducir la base tributaria o dejar fuera de un gravamen o tasa a determinados sujetos.

En torno a la categoría de REFIPRE, la OCDE ha modificado los criterios de calificación desde 1998, cuando emitió el primer reporte sobre este tópico. Entonces, se dijo que existían 4 factores clave y 8 elementos utilizados para calificar si un REFIPRE es o no lesivo. Los factores clave ${ }^{9}$ identificados entonces, fueron los siguientes:

a. El régimen establece un tipo de gravamen efectivo cero o reducido para la renta procedente de actividades financieras y de la prestación de otros servicios geográficamente móviles.

b. El régimen esta compartimentado en relación con la economía

15 acciones y la $5^{\text {a }}$ está orientada a dar elementos para prevenir la competencia fiscal nociva que se da a través de REFIPRES, principalmente. Cfr. OCDE, Plan de acción contra la erosión de la base imponible y el traslado de beneficios, París, OECD, 2014, http://dx.doi.org/10.1787/9789264207813-es, pp. 13-14.

${ }^{8}$ OCDE, Combatir las prácticas fiscales perniciosas, teniendo en cuenta la transparencia y la sustancia. Acción 5. Informe final 2015, Paris, OCDE, 2016, http:/dx.doi. org/10.1787/9789264267107-es, p. 21.

${ }^{9}$ Ibidem, p. 22 y Cfr. Harmful Tax Competition... cit., pp. 26-30. 
nacional. ${ }^{10}$

c. El régimen padece una falta de transparencia (por ejemplo, los detalles del régimen o su aplicación no están claros o evidentes, o hay una supervisión regulatoria o una declaración o comunicación financiera inadecuada).

d. No hay intercambio de información efectivo en lo que se refiere al régimen.

Para 2018, la OCDE modificó los criterios de evaluación, señalando 5 factores clave y 5 factores auxiliares. Los cuatro factores claves de 1998 se replican, pero se incluye un quinto elemento sobresaliente: "e. El régimen es inadecuado en requerir actividades sustanciales." 11 Para entonces, el criterio de actividad sustancial toma mayor relevancia con motivo de la modernización del trabajo sobre prácticas perniciosas, junto con la verificación de intercambio efectivo de información entre países. ${ }^{12}$

De estos factores relevantes, el que nos interesa para este análisis es el que se refiere a la falta de transparencia, ${ }^{13}$ relacionada con los detalles del

${ }^{10}$ Es decir, que el régimen tenga una aplicación limitada, puede ser sólo para extranjeros o para empresas que no participan en el mercado interno. Cfr. Ramírez Figueroa, Enrique, "Los regímenes fiscales preferentes", en Pérez Robles, Arturo (coord.), Los convenios de doble imposición y su interrelación con las medidas para prevenir el abuso en su aplicación, México, Themis, 2011, p. 173.

11 OCDE, Harmful Tax Practices - 2018 Progress Report en Preferential Regimes: Inclusive Framework on BEPS: Action 5, OECD/G20 Base Erosion and Profit Shifting Project, Paris, OCDE, 2019, http://dx.doi.org/10.1787/9789264311480-en, pp. 13, 40-41.

12 OCDE, Combatir las prácticas fiscales perniciosas... cit., p. 25.

${ }^{13}$ En materia fiscal existen diversas formas en que se utiliza el concepto de transparencia, pero para fines de este análisis lo utilizaremos como el requisito que debe cumplirse para no calificar como régimen preferencial. Desde otros puntos de vista también fiscales, la transparencia puede encontrarse como: a) entidades transparentes. Calificación que reciben ciertas entidades o figuras no consideradas como contribuyentes del ISR en el país en que están constituidas o tienen su administración principal o sede de dirección efectiva y sus ingresos son atribuidos a sus miembros, socios, accionistas, o beneficiarios; b) intercambio transparente, que se observa cuando existe un intercambio pleno de información entre jurisdicciones fiscales; c) principio de transparencia conte- 
régimen, su aplicación y la inadecuada supervisión regulatoria o financiera. Sobre este aspecto, la OCDE señala que:

A lack of transparency may arise from the way in which a regime is designed and administered. For example, where the details of the regime or its application are not apparent, or there is inadequate regulatory supervision or financial disclosure. ${ }^{14}$

1. A lack of transparency may arise because:

2. Favourable administrative rulings (e.g., regulatory, substantive, and procedural rulings) are given, allowing a particular sector to operate under a lower effective tax environment than other sectors [...].

3. Special administrative practices may be contrary to the fundamental procedures underlying statutory laws. This may encourage corruption and discriminatory treatment, especially if the practices are not disclosed. Such practices can also make it more difficult for other countries to enforce ther tax laws. Thus, a regime where the tax rate and base are not negotiable, but where administrative practices and enforcement do not conform with the law or do not stipulate the conditions of applicability, may be considered as potentially harmful.

4. If the general domestic fiscal environment es such than the laws are not enforced in line with the domestic law, this could make an otherwise legitimate regime harmful [...].1.

nido en los convenios para evitar la doble tributación, que obliga a las partes a publicar los cambios legislativos sustantivos que puedan afectar a los residentes de su contraparte y, d) transparencia fiscal, que obliga a los contribuyentes a presentar su información fiscal a las autoridades y descubrir sus operaciones relevantes. Cffr. Roa Jacobo, Juan Carlos, "Transparencia fiscal, residencia y acuerdos de intercambio de información tributaria”, en Ríos Granados, Gabriela (coord.), Derecho internacional tributario, México, PorrúaUNAM, 2010, p. 193 y Revilla Martínez, Eduardo, "Transparencia fiscal y acuerdos de intercambio de información tributaria”, en Ríos Granados, Gabriela (coord.), Derecho internacional tributario, México, Porrúa-UNAM, 2010, p. 220.

${ }^{14}$ OCDE, Harmful Tax Practices... cit., p. 14.

15 OCDE, Harmful Tax Competition... cit., pp. 28-29. 
Es este requerimiento de transparencia, el que consideramos incumplido en el país a través de la RMF. En efecto, para la OCDE, la falta de transparencia puede derivar de la forma en que el régimen es diseñado y administrado, cuando los detalles del mismo o de su aplicación no son claros o existe una inadecuada supervisión regulatoria o financiera.

Asimismo, algunos de los factores que ayudan a identificar esta falta de transparencia son: la existencia de reglas administrativas favorables (regulaciones, reglas sustantivas o de procedimiento) diseñadas para cierto sector, que les permite operar en condiciones preferenciales que a otros sectores; prácticas administrativas especiales que pueden ser contrarias a los procedimientos fundamentales establecidos en leyes, ya que aun y cuando no se negocien bases y tasas impositivas, estas prácticas administrativas y aplicación contrarias a la legislación pueden ser consideradas potencialmente perjudiciales y, en general, un ambiente fiscal en donde las leyes no son aplicadas en la línea marcada por las mismas leyes, puede implicar prácticas de competencia indebida.

En los numerales siguientes abundaremos en la búsqueda y demostración de supuestos que contienen beneficios preferenciales otorgados a través de disposiciones administrativas, cuyos motivos para su diseño y supervisión regulatoria y financiera -como dice la OCDE- son inadecuados o inexistentes.

\section{RESOLUCIÓN MISCELÁNEA FISCAL}

La resolución miscelánea fiscal, nombre genérico con el que se conoce al conjunto de reglas administrativas que se emiten anualmente con la intención -se dice- de asistir a los contribuyentes, facilitar la aplicación de las disposiciones legales y el cumplimiento de sus obligaciones fiscales, 
ha sido objeto de múltiples análisis que podrían reducirse a dos posturas: es o no inconstitucional por contener obligaciones que rebasan lo establecido legalmente. ${ }^{16}$ No ha sido, sin embargo, analizada desde la óptica que ahora propondremos, en relación con la falta de procedimientos y transparencia que implica su emisión, ni las consecuencias fiscales nacionales e internacionales que generan ciertas disposiciones perdidas en el armatoste que resulta su publicación.

Año como año, con el nombre de Resolución Miscelánea Fiscal y sus Anexos, se publican conjuntamente tres tipos de pronunciamientos de la autoridad fiscal, realizados con fundamento en los artículos 33, fracción I, inciso g), ${ }^{17}$ h) y penúltimo párrafo, relacionado con el artículo $35 \mathrm{del}$

${ }^{16}$ En efecto, este es el análisis que se realiza mayoritariamente, ya que parte del supuesto de que el artículo 31, fracción IV de la Constitución prevé el principio de legalidad tributaria, en razón del cual las contribuciones y sus denominados elementos esenciales deben contenerse en una norma formalmente legislativa; así, cuando se analiza la RMF, se busca preferentemente verificar si a través de una regla miscelánea se incumple tal imperativo constitucional, en consonancia con el principio de seguridad jurídica. Cfr. Ríos Granados, Gabriela, "Naturaleza jurídica de las reglas generales en materia tributaria”, en Documentos de trabajo del Instituto de Investigaciones furídicas, México, UNAM, IIJ, 2003, pp. 3-4; Reyes Bustamante, Andrés, "La miscelánea fiscal y los principios de legalidad y seguridad jurídica”, en Consultorio fiscal, No. 483, $1^{\mathrm{a}}$. quincena, octubre 2009, México, UNAM, FCyA, 2009, pp. 29-35; Velázquez Meléndez, Vicente, "La resolución miscelánea fiscal ¿es legal su aplicación?", en Nuevo consultorio fiscal, No. 434, México, UNAM, FCyA, pp. 64-68.

17 Para Cuauhtémoc Reséndiz, Dionisio Kayne y Juan Carlos Pérez, este fundamento sólo permite a la autoridad publicar las mencionadas disposiciones, pero no así emitirlas; para ellos, estas reglas están en el marco de las facultades reglamentarias del Ejecutivo o bien, en el marco de las facultades indelegables del Secretario de Hacienda. Cfr. Reséndiz Núñez, Cuauhtémoc, "La resolución miscelánea en materia fiscal: una aproximación”, en Lex, difusión y análisis, 3a . época, año V, junio 2002, número 84, México, 2002, p. 17; Kayne, Dionisio J., "Constitucionalidad y juridicidad de a resolución miscelánea fiscal”, en Nuevo consultorio fiscal, Año 15, No. 286, 2a. quincena de julio de 2001, México, UNAM, FCyA, 2001, pp. 24-27; Pérez Góngora, Juan Carlos, "Constitucionalidad de la miscelánea fiscal”, en Tribunal Federal de Justicia Fiscal y Administrativa a los LXX años de la ley de justicia fiscal, Tomo II, México, TFJFA, 2006, pp.161-175. 


\section{Código Fiscal de la Federación (CFF):}

"Disposiciones de carácter general"18 necesarias para el mejor cumplimiento de las facultades de las autoridades y con la finalidad de proporcionar asistencia a los contribuyentes. Estas disposiciones, conocidas como reglas, cuando se refieran al sujeto, objeto, base, tasa o tarifa, no generarán obligaciones o cargas adicionales a las establecidas en las propias leyes fiscales.

Criterios no vinculativos; en la misma línea que las reglas, se emiten para proporcionar asistencia a los contribuyentes, se publican en el Anexo 3 de la RMF y contienen la interpretación de las disposiciones legales vinculada con conductas que pueden considerarse infractoras de la ley.

"Criterios normativos", contenidos en el Anexo 7 de la RMF, en teoría deben ser de carácter interno que los funcionarios fiscales emiten para dar a conocer a las diversas dependencias el criterio a seguir para la aplicación de las disposiciones fiscales. De estos criterios, el CFF dice, no nacerán obligaciones para los particulares y únicamente derivarán derechos a su favor, cuando se publiquen en el Diario Oficial de la Federación (DOF).

Se advierte con meridiana claridad, que la RMF, en su vertiente de "reglas y criterios no vinculativos", se encuentran en el ámbito de proporcionar "asistencia" a los contribuyentes; es decir, deben constituir un conjunto de disposiciones que faciliten el cumplimiento de las obligaciones fiscales de los destinatarios. Mientras que los criterios internos se dirigen a los funcionarios fiscales y podrán contener derechos a favor de los particulares. Aunque esos supuestos derechos están previstos en el CFF sólo

${ }^{18}$ Conforme al artículo 39, fracción II del CFF, el Ejecutivo Federal es quien tiene la facultad de emitir resoluciones de carácter general, con las medidas relacionadas con la administración, control, forma de pago y procedimientos señalados en las leyes fiscales, sin variar las disposiciones relacionadas con el sujeto, el objeto, la base, la cuota, la tasa o la tarifa de los gravámenes, las infracciones o las sanciones de las mismas, a fin de facilitar el cumplimiento de las obligaciones de los contribuyentes. 
en el caso de los criterios, lo cierto es que los órganos jurisdiccionales han considerado de forma genérica que estos derechos pueden existir en todo el conjunto de la RMF e incluso han llegado al extremo de no advertir que, en ocasiones, esos presuntos derechos significan exenciones "de facto" de las obligaciones fiscales.

Lo que demostraremos a continuación supera la mixtura realizada por los órganos jurisdiccionales, ya que además de su dudoso contenido, lo cierto es que la RMF no es un ordenamiento susceptible de verificación, por la secrecía en sus procedimientos de emisión y falta de obligaciones que permitan confirmar si sólo está sirviendo para proporcionar asistencia a los contribuyentes o sí en realidad, bajo la ilusión de contener derechos, está desaplicando o sustituyendo la legislación en detrimento de los objetivos para los cuales fueron diseñadas las leyes fiscales.

\section{NATURALEZA JURÍDICA}

En la doctrina y en la jurisprudencia existe la aceptación unánime de que la RMF contiene disposiciones materialmente legislativas, generales, abstractas e impersonales; en lo que existe división es en cómo calificar la función de la RMF. Así se ha considerado a la RMF ya como instrumento facilitador de la aplicación de las disposiciones legales, como complementario de la ley, como aparato normativo que permite otorgar derechos a los contribuyentes y, más recientemente, como disposiciones que pueden modificar los denominados elementos esenciales de las contribuciones o hasta ser considerada "erróneamente" como producto de la nueva visión reguladora del Estado. 
El enfoque de "facilitador o de asistencia" es el que establece el CFF para la RMF y tiene su origen en los años ochenta, cuando se buscó facilitar a los contribuyentes el conocimiento de las disposiciones de la autoridad fiscal que, hasta entonces, se publicaban como circulares en una revista de la autoridad hacendaria. En este contexto, las reglas de la RMF son decisiones administrativas emitidas para reglamentar la aplicación de la ley, pero sujetas a su supremacía, por lo que la RMF no puede derogar, limitar o excluir lo dispuesto en la legislación. ${ }^{19}$

En una segunda vertiente, como "complementaria de la ley", se piensa que en tanto exista una cláusula habilitante, la RMF podrá cumplir con el papel de desarrollar las normas legales que prevén o autorizan su emisión.

El enfoque más explotado, el que considera que a través de la RMF pueden "otorgarse derechos", sobrepasa lo establecido en el CFF, ya que en este ordenamiento se prevé que sólo los criterios normativos podrán contener derechos para los contribuyentes; sin embargo, la interpretación jurisdiccional ha extendido esa posibilidad a todo el contenido de la RMF.$^{20}$ No obstante, el Poder Judicial no ha sido eficaz en determinar el límite de esos derechos, cuando en la praxis esas reglas se convierten en normas que exentan o disminuyen el alcance de la obligación sustantiva tributaria en clara contravención a la prohibición prevista en el artículo 28 constitucional; quizá la razón se deba al hecho de que quien recibe una facilidad que implica un no pago o un pago menor a su capacidad contributiva, no tiene un perjuicio que reclamar ante los Tribunales.

En una perspectiva más reciente, el Poder Judicial considera que sí es posible a través de la RMF "determinar elementos esenciales de las

\footnotetext{
${ }^{19}$ Pérez de Acha, Luis M., "Resolución miscelánea fiscal”, en Lex, difusión y análisis, $3^{a}$. época, año V, junio 2002, número 84, pp. 8-9.

20 Tesis 1a. CXII/2017 (10a.), Gaceta del Semanario Judicial de la Federación, Décima Época, Primera Sala, Libro 46, septiembre de 2017, Tomo I, p. 215.
} 
contribuciones"; y aunque desde la teoría clásica de los elementos de las contribuciones y del principio de legalidad tributaria, el sujeto, objeto, base, tasa y época de pago deben estar determinadas en una norma formalmente legislativa, lo cierto es que para la Corte, en elaboración de su propia teoría, esos elementos son de dos tipos: cualitativos (sujeto, objeto) y cuantitativos (base y tasa), pudiendo la autoridad fiscal detallar los cuantitativos en la RMF. ${ }^{21}$

Una última postura en torno a la naturaleza de la RMF, es aquélla que considera su emisión como producto de la "potestad regulatoria del Estado". Adelantábamos el desacuerdo con esta idea que encontramos en un Tribunal Colegiado, ${ }^{22}$ quien increíblemente decide convertir al Servicio de Administración Tributaria (SAT) en un órgano regulador “cuya encomienda institucional consiste en regular técnicamente 'ciertas actividades económicas o sectores sociales' de manera independiente” y, por lo tanto, "no debe someterse a las exigencias o límites de los principios de reserva de ley ni de subordinación jerárquica, ya que éstos, al estar sujetos al principio de legalidad como restricciones, son exclusivos de la facultad reglamentaria del Presidente de la República -acotada por la propia ley-”.

21 Tesis 2a. LV/2016 (10a.), Gaceta del Semanario Judicial de la Federación, Décima Época, Segunda Sala, Libro 34, septiembre de 2016, Tomo I, p. 847 y Tesis 2a. XXIX/2017 (10a.), Gaceta del Semanario fudicial de la Federación, Décima Época, Segunda Sala, Libro 40, marzo de 2017, Tomo II, p. 1404. Adelantamos que no compartimos este criterio porque la base del impuesto es una forma de concretizar el principio de proporcionalidad en el pago de los impuestos medida por la capacidad contributiva de las personas, por lo que debe estar definida en una ley y no quedar al arbitrio de la autoridad administrativa.

22 Tesis: I.4o.A.121 A (10a.), Gaceta del Semanario fudicial de la Federación, Décima Época, Tribunales Colegiados de Circuito, Libro 58, septiembre de 2018, Tomo III, p. 2310 . 
Habría mucho que decir de estas ocurrencias jurisdiccionales, pero bastará con mencionar una tercia de precisiones sobre lo que son los órganos reguladores, las actividades económicas y la naturaleza y función del SAT.

Primero, los órganos reguladores "de mercado", aparecen en lo que ahora se denomina "Estado Regulador", lo cual no significa que el Estado tenga una nueva función (contar con un sistema jurídico es parte de la naturaleza de cualquier Estado), sino que esta denominación surge en México a partir de su inserción en las economías de mercado. En dicho contexto, el Estado regulador sigue "un modelo para atender necesidades muy específicas en la sociedad posindustrial (suscitadas por el funcionamiento de mercados complejos), que deposita en ciertas agencias independientes -de los órganos políticos y de los entes regulados- la regulación de ciertas cuestiones especializadas sobre la base de disciplinas/o racionalidades técnicas”. ${ }^{23}$ En dicha nueva visión, surgen algunas agencias especializadas o, como dice la tesis en comento, órganos reguladores que tienen como función regular técnicamente ciertas actividades económicas o sectores y, cuando tienen el carácter de organismos constitucionales autónomos, se ha defendido su autonomía desvinculando sus regulaciones de los principios de supremacía legal, reserva de ley o legalidad, siempre que sus disposiciones sean emitida exclusivamente para el cumplimiento de su función regulatoria en el sector de su competencia. ${ }^{24}$

Segundo, de acuerdo al Instituto Nacional de Estadística y Geografía (INEGI), ${ }^{25}$ una "unidad económica es una entidad productora de bie-

${ }^{23}$ Suprema Corte de Justicia de la Nación, Controversia constitucional 117/2014, en http://wrwrw2.scjn.gob.mx/jurídica/engroses/3/2014/9/3_175161_2453.doc, párrafo 325.

${ }^{24}$ Ibidem, párrafos 238, 255, 260, 272, 284, 295, 306-307, 313, 322, 329, 335, 338340, 354, 358-359 у 363.

${ }^{25} \mathrm{El}$ concepto a seguir para detallar actividad o sector económico es el que proporciona el INEGI en términos de del artículo 26, apartado B de la Carta Magna, en donde se precisa que, la información y datos del Sistema, normado y coordinado por el 
nes o servicios. Y una "actividad económica" es un conjunto de acciones realizadas por una unidad económica con el propósito de producir o proporcionar bienes y servicios", mientras que un "sector económico" “constituye el nivel más agregado de la clasificación y 'agrupa a las actividades' de una misma naturaleza, con similar función de producción en el sentido más amplio". ${ }^{26}$

Tercero, según los artículos $1^{\circ}$ y $2^{ }$de su Ley, el SAT es un órgano desconcentrado de la Secretaría de Hacienda y Crédito Público (SHyCP), con carácter de autoridad fiscal cuya responsabilidad es aplicar la legislación fiscal y aduanera con el fin de que las personas físicas y morales contribuyan proporcional y equitativamente al gasto público, así como fiscalizar a los contribuyentes y facilitar e incentivar el cumplimiento voluntario.

Conforme a las tres precisiones anteriores, el SAT no es un órgano regulador de mercado; su función principal, cuando se dirige a los contribuyentes, es lograr que éstos contribuyan en forma proporcional y equitativa al gasto público, más no regular a los contribuyentes en sus actividades en forma técnica y mucho menos calificar sí o no dichas actividades son necesarias para atender a la sociedad o para mantener un equilibrio en el mercado de que se trate. De ahí que consideramos que el Tribunal Colegiado parte de una premisa incorrecta en torno a la naturaleza del SAT y, en consecuencia, tergiversa la naturaleza de la RMF que se emite año con año.

INEGI, son oficiales y de uso obligatorio para los tres niveles de gobierno.

${ }^{26}$ En esta estructura, la clasificación económica se divide en sectores, subsectores, ramas, subramas y clase de actividades. Instituto Nacional de Estadística y Geografía, Sistema de Clasificación Industrial de América del Norte, México, SCIAN 2018, http://internet.contenidos.inegi.org.mx/contenidos/Productos/prod_serv/contenidos/espanol/bvinegi/productos/nuevo_estruc/702825099695.pdf, pp. VII-IX. 
De entre todas las posibilidades que se le atribuyen a la RMF, la postura que nos preocupa es la que permite a la autoridad administrativa incidir en las obligaciones de los contribuyentes, con el indeleble sustento de estar otorgando derechos, pero que en realidad se utiliza como instrumento de creación de regímenes tributarios particulares.

En el ámbito doméstico, esto se discute con la calificación de reglas constitucionales o inconstitucionales, pero en el ámbito internacional su trascendencia puede llegar a (des)calificar al país como una jurisdicción en la que se permiten REFIPRES que impacta a la recaudación nacional y permite a los demás países imponer sanciones o medidas de índole económico, principalmente, tanto para desalentar a México a realizar dichas prácticas indebidas, como para hacer que sus nacionales regresen las fuentes de ingresos a sus países de residencia.

\section{TRANSPARENCIA}

¿Cómo puede la RMF convertirse en un elemento de constitución de REFIPRES?, pensamos que esa posibilidad se activa desde que no existe un acuerdo jurisdiccional en respetar los límites legales que le son impuestos a la RMF y, además, a partir de que no existe transparencia en torno a cómo se formula, sí o no se llevan a cabo estudios jurídicos, económicos y análisis de los impactos en los ingresos y en el presupuesto que pueden derivar de dichas disposiciones. Como anunciábamos antes, esta falta de transparencia, en el sentido en el que lo estamos usando en este documento, está considerada por la OCDE como un parámetro que cuestiona la lealtad tributaria de los países. 
La RMF se emite con fundamento en los artículos 16 y 31 de la Ley Orgánica de la Administración Pública Federal (LOAPF), 33, fracción I, inciso g) del CFF, 14, fracción III de la Ley del Servicio de Administración Tributaria y 8, primer párrafo del Reglamento Interior del Servicio de Administración Tributaria (RISAT). ${ }^{27}$

$\mathrm{El}$ artículo 16 de la LOAPF, se refiere a la delegación que pueden realizar los titulares de las Secretarías de Estado para el trámite y resolución de los asuntos de su competencia. El artículo 31 del mismo ordenamiento, indica los asuntos que corresponden a la SHyCP en XXXII fracciones, pero la publicación del DOF no indica cuál de esas atribuciones está siendo delegada al Jefe/a del SAT para la emisión de la RMF.

El artículo 33, fracción I, inciso g) del CFF que, en el ánimo de mejorar el cumplimiento de las facultades de la autoridad, le permite proporcionar asistencia, mediante la publicación anual de las resoluciones que establezcan disposiciones de carácter general agrupándolas de manera que faciliten su conocimiento por parte de los contribuyentes; pero, cuando las resoluciones que se refieran a sujeto, objeto, base, tasa o tarifa, no generarán obligaciones o cargas adicionales a las establecidas en las leyes.

El artículo 14 de la Ley del SAT, señala las atribuciones del Jefe/a de dicha entidad y, en su fracción III indica que éste/a podrá expedir las disposiciones necesarias para aplicar eficientemente la legislación fiscal y aduanera, haciendo del conocimiento de la Junta de Gobierno aquéllas que considere de especial relevancia. Finalmente, el artículo $8^{\circ}$, primer párrafo del RISAT, califica al Jefe/a del SAT como la máxima autoridad administrativa de dicho órgano desconcentrado, a quien le corresponde el trámite y resolución de los asuntos de su competencia que se detallan en una multiplicidad de fracciones en ese precepto.

\footnotetext{
${ }^{27}$ Tomado de la publicación en DOF del 29 de abril de 2019, en el cual se dio a conocer la RMF en vigor.
} 
Ya habíamos apuntado cierta discusión doctrinaria en torno a sí el artículo 33 del CFF es suficiente ${ }^{28}$ para sustentar la emisión de la RMF por parte del SAT; ahora además advertimos que los preceptos que le acompañan y que sirven de fundamento para su publicación, son extremadamente genéricos y, en varios casos, se componen de una serie de fracciones que no se citan siquiera para conocer en forma exacta cuál de las atribuciones se está ejerciendo con la emisión y publicación de la RMF.

Empero, lo que nos resulta relevante de esa fundamentación, es la ausencia total de disposiciones que detallen el procedimiento de emisión y más aún, que expliquen si es necesaria o no la existencia de análisis previos y posteriores a dicha $\mathrm{RMF},{ }^{29}$ y que confirma nuestra postura en torno al incumplimiento del parámetro de "transparencia" que utiliza la OCDE para calificar la existencia de REFIPRES.

Aunado a lo anterior, sostenemos que tratándose de reglas misceláneas que legislen la aplicación o desaplicación de disposiciones legales, sí es necesario valorar el impacto que sobre los ingresos y egresos nacionales tendrán esas reglas, ya que en esencia pueden representar "gastos fiscales" ${ }^{\prime \prime 30}$ no contemplados en las leyes de la materia e incidir en los ingresos y presupuesto autorizados, sin que se hayan hecho los análisis

\footnotetext{
${ }^{28}$ Supra, notas 17 y 18.

${ }^{29}$ No obstante, a través del Sistema Infomex realizamos las solicitudes números 0210000168119, 0000600279519 y 0610100128219, dirigidas a la Oficina de la Presidencia de la República, a la SHyCP y al SAT, pidiendo el documento en el cual conste el procedimiento que se debe llevar a cabo para emitir la RMF. Las primeras autoridades manfiestaron no tener competencia para rendir la información. La tercera autoridad indicó no estar obligada a realizar o documentar análisis sobre los efectos de la Miscelánea, afirmando ser mera compiladora de lo que le remiten la SHyCP y otras áreas del SAT.

${ }^{30}$ Los gastos fiscales son las cantidades que dejará de recaudar la administración pública por la concesión de ventajas fiscales a ciertos contribuyentes o determinados sectores económicos, Los gastos fiscales consisten en el No ingreso o en el ingreso negativo para la administración. Cfr. https://economipedia.com/definiciones.
} 
que, en cumplimiento de los principios de control y rendición de cuentas $^{31}$ relacionados con los ingresos públicos, sí se exigen para la emisión de las leyes, ${ }^{32}$ pero dejan de requerirse cuando reglas de menor jerarquía pueden tener un oscuro impacto recaudatorio.

\section{REFIPRES. LEY INHIBITORIA VS RMF PERMISIVA}

En el Título VI de la LISR, se precisan las reglas para inhibir operaciones en jurisdicciones que se consideren desleales en cuanto a su régimen preferencial de tributación. Ese Título pretende desalentar y fiscalizar la realización de operaciones con entidades o figuras sujetas a REFIPRES, desde dos perspectivas: a) empresas nacionales que "invierten" en el extranjero y, b) empresas nacionales que hacen "pagos" a empresas en el extranjero; en ambos casos, cuando se sospecha de que inversiones y pagos se dirijan a regímenes preferenciales. Para efectos de este estudio, dividiremos el análisis de los REFIPRES a partir de estas dos perspectivas, confrontando la norma legal con las disposiciones administrativas que restrinjan su significado y alcance.

\section{INVERSIONES DE MEXICANOS EN EL EXTRANJERO}

El Título VI. De los regímenes fiscales preferentes y de las empresas multinacionales, Capitulo I. De los regímenes fiscales preferentes de la LISR, contiene el

${ }^{31} \mathrm{El}$ artículo XV de la Declaración Universal de los Derechos del Hombre y del Ciudadano de 1789, ya mencionaba que "la sociedad tiene derecho a pedir a todos sus agentes cuentas de su administración”.

${ }^{32}$ En efecto, en el artículo 32 de la Ley de Ingresos de la Federación se exige que toda iniciativa en materia fiscal debe incluir el impacto recaudatorio de cada una de las medidas propuestas; es decir, explicar cómo la legislación incidirá en los ingresos federales. Por su parte, la Ley Federal de Presupuesto y Responsabilidad Hacendaria, en sus artículos $1^{\circ}, 18$ y 77, también obliga a las autoridades a evaluar e indicar cómo impactará en el presupuesto, toda propuesta de aumento o creación de gasto, subsidios y, en general, cualquier proyecto de ley o decreto que presente el Ejecutivo. 
esquema de pago del ISR de los residentes en México ${ }^{33}$ por los ingresos sujetos a REFIPRES que obtengan a través de entidades o figuras jurídicas extranjeras. Desde esta perspectiva, se deben tener en consideración dos premisas: a) el sujeto del impuesto es un residente en el país y, b) este sujeto recibe un trato diferenciado en el impuesto, en razón de que dicho ingreso pudiera NO estar gravado o mínimamente gravado en la jurisdicción considerada con REFIPRE.

En general, un residente en México debe pagar el ISR por los ingresos sujetos a REFIPRES que obtenga: a) a través de entidades o figuras jurídicas extranjeras en las que participen, directa o indirectamente, b) a través de entidades o figuras jurídicas extranjeras que sean transparentes fiscales ${ }^{34}$ en el extranjero. En estos casos, el contribuyente pagará el impuesto en el mismo ejercicio en el que se genere el ingreso, con independencia de que haya sido o no distribuido por la entidad o figura extranjera.

Los ingresos que se considerarán sujetos a REFPRE, serán aquellos no gravados en el extranjero o cuando lo estén con un ISR inferior al $75 \%$ del ISR que se causaría y pagaría en México, ya sea por la aplicación de una disposición legal, reglamentaria, "administrativa", de una resolución, autorización, devolución, acreditamiento o cualquier otro procedimiento. Con algunas excepciones, los ingresos pasivos, serán los castigados con este régimen, al contrario de los ingresos derivados de actividades empresariales o activas. Los ingresos se determinarán por cada una de las operaciones que los genere, salvo que se trate de ingresos obtenidos como socio, accionista o beneficiario de un residente en el

\footnotetext{
${ }^{33}$ Cuando hablemos de residentes en México, también estaremos abarcando a los residentes en el extranjero con establecimiento permanente en el país; incluso cuando nos refiramos a los mexicanos o nacionales, para efectos didácticos también estaremos hablando de estos dos sujetos, aun y cuando sabemos que mexicanos y nacionales son connotaciones políticas y sociológicas distintas a la residencia fiscal.

${ }^{34}$ Ver supra nota 13.
} 
otro país, en cuyo caso se considerará la utilidad o pérdida que generen todas las operaciones realizadas en ella. Los ingresos no se acumularán a los demás del contribuyente.

En todo caso, se considerará el control efectivo que tenga el nacional sobre las entidades y figuras extranjeras y, en función de lo anterior, el contribuyente tiene la obligación de tener a disposición la contabilidad de las entidades o figuras en las que participe, así como presentar una declaración informativa de dichas inversiones.

La RMF se ocupa de los REFIPRES en su capítulo 3.19, en el que aparecen distintas reglas que combinan el quehacer de dichas disposiciones administrativas, ya que igual se encuentran reglas que son de franca asistencia a los contribuyentes, como reglas que otorgan derechos o beneficios y reglas que legislan la (des)aplicación del régimen.

Como "reglas de asistencia", podemos clasificar las reglas 3.19.5. Comprobantes de ingresos no sujetos a regímenes fiscales preferentes (vigente desde 2005, como regla 3.24.8, con pocas modificaciones a la fecha); 3.19.6. Solicitud de autorización para no aplicar las disposiciones del Título VI, Capítulo I de la Ley del ISR, a los ingresos pasivos generados por entidades o figuras jurídicas del extranjero que tengan autorización para actuar como entidades de financiamiento por las autoridades del país en que residan; 3.19.9. Aviso de enajenación de acciones derivada de una reestructuración internacional; 3.19.10. Declaración informativa sobre sujetos ubicados en regímenes fiscales preferentes y 3.19.11. Contenido de la declaración informativa de entidades transparentes. Estas reglas indican a los contribuyentes los formatos y contenidos mínimos que deben hacer llegar a las autoridades en cumplimiento de las disposiciones legales aplicables a su situación. 
Reglas de "beneficios o derechos", consideramos son las reglas 3.19.4. Ingresos de personas físicas no sujetos a regímenes fiscales preferentes (que excluye del régimen ingresos mínimos y que ha existido desde 2005 con la numeración 3.24.6); 3.19.7. Consolidación de ingresos sujetos a regímenes fiscales preferentes (que facilita la determinación del impuesto en función de cómo lo realizan en el extranjero, regla creada desde 2008 con el número I.3.23.8.) y 3.19.8. Presentación de declaración informativa de forma espontánea (en la cual se considera cumplida una obligación aun y cuando se haga en forma extemporánea pero completa; esta regla existe desde 2005 con el número 3.24.3).

Pero, como disposiciones que "legislan" el régimen, encontramos la regla 3.19.1. Ingresos transparentes no sujetos a regímenes fiscales preferentes, que no sólo desaplica ${ }^{35}$ lo establecido en el artículo 176, párrafo $7^{\text {o }}$ de la LISR, sino que en forma muy interesante nos presenta un supuesto en donde el pagador es, a la vez, el receptor de ese ingreso que deberá acumular, pudiendo deducir los gastos para iprestar(se)? el servicio.

En efecto, el artículo 176, párrafo $7^{\circ}$ de la LISR establece que tendrán el tratamiento fiscal de REFIPRES "los ingresos que se obtengan a través de entidades o figuras jurídicas extranjeras que sean transparentes fiscales en el extranjero, aun cuando dichos ingresos no tengan un régimen fiscal preferente"; la regla desde su título indica que ciertos ingresos no estarán sujeto al tratamiento previsto en ley, sino que deberán pagar el impuesto conforme a la regla 3.18.25, en la cual se establece que cuando una entidad

${ }^{35}$ Una regla con la finalidad de determinar los ingresos sujetos a REFIPRES ha estado vigente desde 2005. Primero con el numeral 3.24.1., en 2005 y 2006, que buscaba determinar el régimen considerando la totalidad de las operaciones realizadas por las empresas. En 2007, la regla consideraba la participación en las empresas en las entidades sujetas a REFIPRES. En 2008, la regla I.3.23.1. establecía la revisión del control efectivo para aplicar el régimen; este contenido se repite en 2009 (I.3.23.1) y de 2010 a 2013 (I.3.18.1). Para 2014 (3.19.1) se sigue manteniendo la mención de verificar el control efectivo, lo que para entonces ya se encontraba en el artículo $176,14^{\circ}$ párrafo de la LISR; en ese mismo año se agrega la posibilidad que ahora denominamos autopago. 
transparente sea quien perciba los ingresos de fuente nacional, el impuesto lo causarán sus integrantes como perceptores de esos ingresos, en el mismo año en que lo percibe la figura jurídica extranjera; estos integrantes-residentes nacionales podrán deducir los gastos por la recepción de servicios independientes realizados por dicha figura transparente.

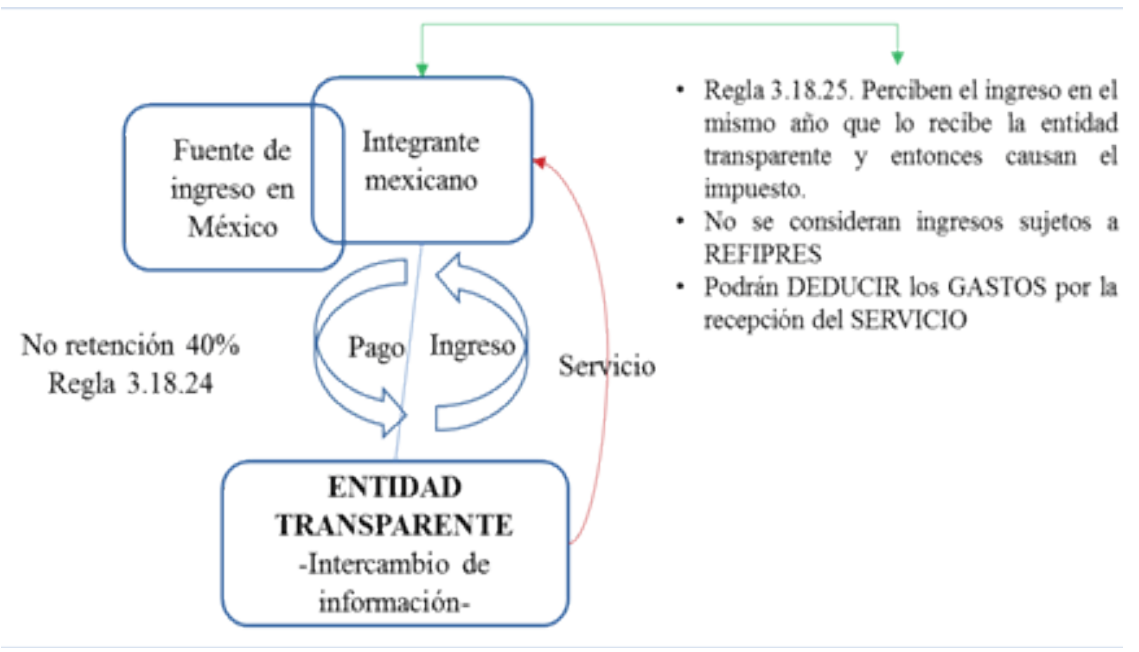

Figura 1. Inversiones y pagos en y para entidades transparentes

Desde luego nos parece una forma muy interesante de reconocer que un residente en México se está -en algún sentido- pagando a sí mismo y ese pago tendrá el tratamiento que refiere la regla; pero esta regla nos genera las siguientes observaciones: Primero, advertimos que un supuesto tan especializado o casuístico, no podría estar así legislado en la LISR, lo cual nos hace dudar de su generalidad. Segundo, nos preguntamos si previamente sería necesario investigar si ese pago es legítimo (sustancia sobre forma) y, en su caso, desincentivar este tipo de operaciones antes que darle el trato diferenciado que les permite planear operaciones en el extranjero y tomar deducciones realizadas fuera del país. 
La lectura anterior de la RMF en el capítulo de REFIPRES, muestra que existe una combinación de objetivos plasmados en la RMF, en algunos casos limitándose a ser un medio de orientación y asistencia a los contribuyentes, como está expresamente definida su función en el CFF, hasta llegar a supuestos en los que se legisla en forma dirigida a determinados contribuyentes, respecto de lo cual sería conveniente conocer ¿cuánto cuesta o cuál es el beneficio para el país, la existencia de una regla que desaplica una norma legal?

De igual forma, nos percatamos que las reglas de orientación, asistencia o facilidades han existido prácticamente sin modificaciones desde la reformulación del régimen en 2005; no así las reglas que legislan, las cuales en algunos casos sólo prevalecen en cuanto a su rubro, pero no en cuanto a su cuestionable o hasta simpático contenido; lo que nos hace preguntarnos respecto de este último tipo de reglas ¿por qué no conocemos "oficialmente" sus motivaciones y los efectos que han hecho que se modifiquen?

\section{PAGOS DE MEXICANOS AL EXTRANJERO ${ }^{36}$}

En el numeral anterior analizamos el pago del impuesto a cargo de los residentes en México que reciben ingresos provenientes de jurisdicciones con REFIPRES. Ahora, desde la perspectiva de pagos con fuente de riqueza ${ }^{37}$ en México, en general pagos realizados por mexicanos a residentes en el extranjero, analizamos la forma en que la LISR prevé el cálculo del impuesto de esos residentes en el extranjero.

\footnotetext{
${ }^{36}$ Los preceptos de la LISR 28, fracción XXIII y 171, tienen sus equivalentes en los artículos 32, fracción XXII, 204 y 205 de la LISR vigentes hasta 2013.

37 "Source of income. The place (or country) where a particular item of income is deemed to originate or where it is deemed to be generated. National rules vary, depending on which concept of source is used". Cfr. OCDE, Glossary... cit.
} 
En el artículo 171 de la LISR se refiere que cuando un residente en otro país reciba ingresos de fuente de riqueza mexicana y esos ingresos sean beneficiados por un REFIPRE en el extranjero, estarán a una retención a la tasa del 40\% sobre dichos ingresos, sin deducción alguna, en vez de aplicar la retención que esté prevista en el Título V. De los residentes en el extranjero con ingresos provenientes de fuente de riqueza ubicada en territorio nacional. Además, en el artículo 28, fracción XXIII de la misma LISR, se indica la no deducibilidad de los pagos realizados a entidades o figuras jurídicas cuyos ingresos estén sujetos a REFIPRES, excepto si el monto de la contraprestación es igual al que hubieran pactado partes no relacionadas en operaciones comparables.

Conforme a los preceptos indicados, se entiende que un residente en México que realice pagos a una entidad o figura extranjera cuyos ingresos estén sujetos a un REFIPRE: a) deberá retener el 40\% de dicho pago por concepto de impuesto y, b) para poder deducir dichos pagos, deberá demostrar que los precios pactados fueron a precio de mercado.

A pesar de que la legislación no impone más condiciones a la aplicación de esta retención, la autoridad administrativa a través de la regla 3.18.24. Retenciones en operaciones con partes relacionadas, indica que la retención sólo será aplicable cuando se realicen operaciones con partes relacionadas. ${ }^{38}$ Pero, la mencionada retención no aplicará, cuando: a) esas partes relacionadas residan en un país con el que México tenga un acuerdo amplio de intercambio de información y, b) cuando las operaciones se realicen con personas No relacionadas; en tales casos, la reten-

\footnotetext{
${ }^{38}$ Se considera que dos o más personas son partes relacionadas, cuando una participa de manera directa o indirecta en la administración, control o capital de la otra, o cuando una persona o grupo de personas participe directa o indirectamente en la administración, control o capital de dichas personas. Tratándose de asociaciones en participación, son partes relacionadas sus integrantes y las personas -partes relacionadas- de tal integrante.
} 
ción no será del 40\%, sino la que corresponda en términos del Título V de la LISR, que en general señala tasas diferentes al $40 \%$.

En nuestra opinión, esta regla desaplica el régimen mencionado anteriormente, ya que decide que no se aplicará a la totalidad de las entidades o figuras cuyos ingresos sean de fuente en el país y residan en una jurisdicción con un régimen de competencia desleal, sino sólo a aquéllos considerados relacionados de un residente nacional. Es decir, bajo la ley y la miscelánea, los escenarios de aplicación y sujetos pasivos obligados son distintos, como se advierte en la siguiente figura:
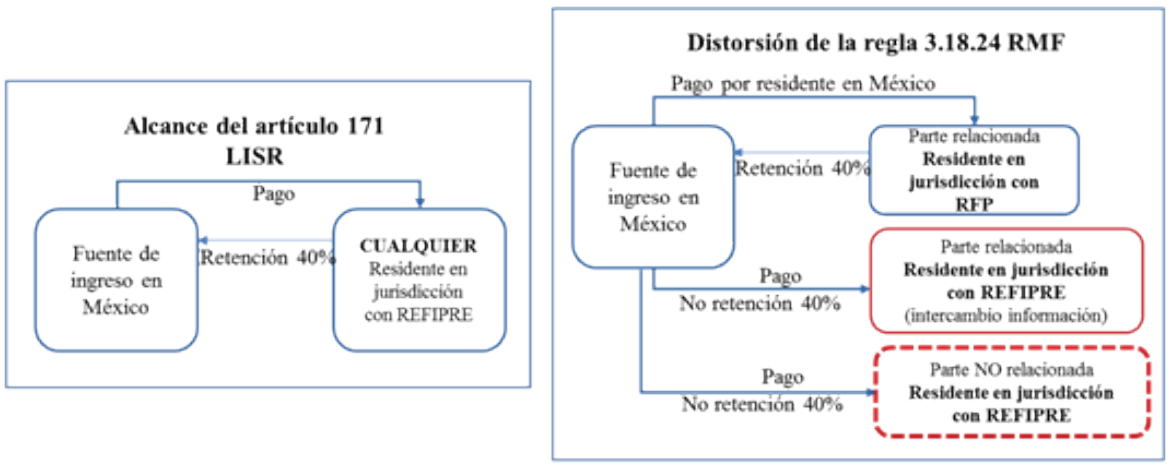

Figura 2. Retenciones sobre pagos vinculados a REFIPRES

Es importante mencionar que el combate a estos regímenes se da desde dos perspectivas y, en este caso, la legislación no toma en cuenta si el pagador nacional tiene interés o vínculo particular con el extranjero, sino el hecho de que -se sabe- esos pagos quedarán sin tributación efectiva y, con el ánimo de desalentar operaciones que en algún punto no paguen impuestos, la legislación eligió castigarlos con la retención del 40\%. 
Sin embargo, la RMF desaplica ese supuesto al considerar que sólo los pagos a partes relacionadas pueden tener el trato legal anunciado, lo cual corrobora que la aplicación de la ley no sigue los parámetros de la ley misma -situación observada por la OCDE en la falta de transparencia descrita previamente-. ${ }^{39}$

En consecuencia, no se ha hecho público el impacto de esta regla, no sólo desde el punto de vista recaudatorio, sino desde el punto de vista en que convierte a le legislación en ineficaz, al no inhibir el total de las operaciones realizadas con sujetos a tributación desleal. Asimismo, desde el punto de vista de los contribuyentes, no se ha reclamado la exclusión de ingresos sujetos a retención del 40\%, ni la supresión de los sujetos que causarían el impuesto a esa tasa, ni de los obligados a retención, a pesar de que en el régimen vigente desde 2005 la regla se ha repetido con distinta numeración ${ }^{40}$ pero con mismos efectos.

\section{MiXTURAS ADMINISTRATIVAS}

Bajo este rubro analizamos algunas disposiciones administrativas que consideramos erróneas por realizar una mixtura entre las dos vertientes que prevé la LISR para inhibir las operaciones con residentes en jurisdicciones con REFIPRES; es decir, aquéllas disposiciones que "confunden" inhibir pagos al extranjero de fuente nacional, con las inversiones en el extranjero

\footnotetext{
${ }^{39}$ Por otra parte, no se pudo comprobar la finalidad oficial de esta regla, debido a la falta de información sobre los objetivos que persigue. Consultamos sobre los motivos, análisis jurídicos o económicos, análisis de impacto presupuestal o en los ingresos que sirvieron de sustento para emitir la regla 3.18.24., pero no obtuvimos ni información, ni documentación que refleje un estudio preliminar y posterior a la emisión de la regla. Sistema Infomex, solicitudes 0210000168219 y 0210000168419.

40 2005-2007 (3.23.9); 2008-2009 (I.3.22.3.), 2010 (I.3.17.15.), 2011 (I.3.17.16.), 2012 (I.3.17.15.), 2013 (I.3.17.14.), 2014 (I.3.17.10.), 2015 (3.18.21.) y 2016-2019 (3.18.24.).
} 
de nacionales, provocando con ello distorsiones y seguramente contribuyendo a las planeaciones fiscales agresivas en contra del fisco mexicano.

El caso paradigmático que encontramos es el criterio número "97/2013/ISR" Ingresos sujetos a regímenes fiscales preferentes. El requisito consistente en no estar sujeto a dichos regímenes, sólo resulta aplicable cuando el residente en el extranjero sin establecimiento permanente en el país es una entidad o figura jurídica a través de la cual obtiene ingresos un residente en México o un residente en el extranjero con establecimiento permanente en el país, de escasa vigencia en el periodo analizado, ${ }^{41}$ pero que implicó desarticular el régimen al combinar los requisitos de las dos formas independientes reguladas en la LISR para inhibir inversiones y pagos vinculados con REFIPRES.

La aplicación de este criterio reduce aún más lo hecho por la regla 3.18.24 de la RMF, en su equivalente I.3.17.14 y I.3.17.10 vigentes en 2013 y 2014, ya que si esta regla reduce a los sujetos obligados a aquéllos considerados partes relacionadas con un residente en México, este criterio además implicó que esas partes relacionadas serían las obligadas pero sólo en la medida en que el nacional reciba ingresos de un residente en el extranjero; situación que desatiende por completo lo establecido en la LISR.

${ }^{41} \mathrm{El}$ criterio se encuentra publicado en la página de internet del SAT y conforme a los datos localizados, fue incorporado en el año de 2013 y derogado al año siguiente. Cfr. Servicio de Administración Tributaria, Oficio No. 600-(04-078-2013-16549, http:// omawww.sat.gob.mx/informacion_fiscal/normatividad/Documentos/criterios_normativos_19122013.pdf y Oficio No. 600-(04-(07-2014-87379, http:/omawww.sat.gob.mx/informacion_fiscal/normatividad/Documentos/criterios_normativos_4otrimestre2014.pdf. 
Anticipación de ingresos provenientes de REFIPRES

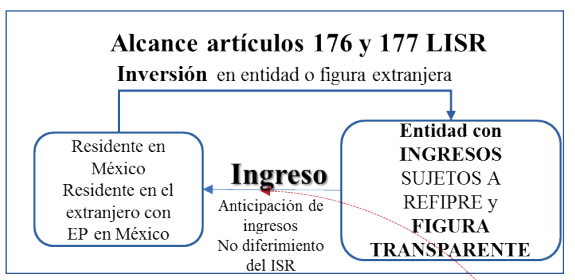

Retenciones sobre pagos vinculados a REFIPRES
Retenciones sobre pagos vinculados a REFIPRFS
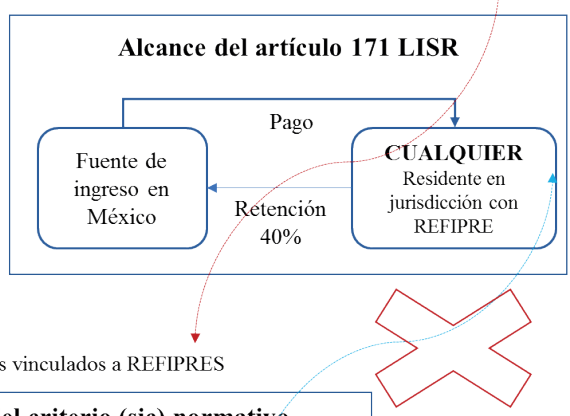

Tergiversación a causa del criterio (sic) normativo

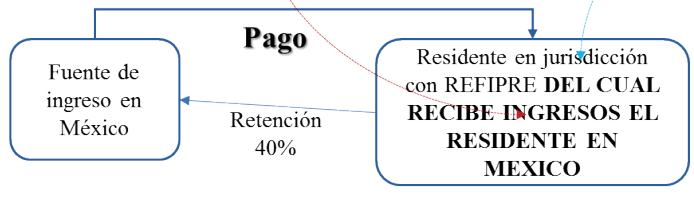

Figura 3. Retenciones sobre pagos vinculados a REFIPRES bajo el criterio (sic) normativo

Pensemos en los escenarios de abuso provocado por la autoridad fiscal al aplicar la regla 3.18.24 y el criterio 97/2013/ISR en análisis. En todos los casos existe fuente de riqueza y/o pago realizado por un residente en México, pero los efectos serán distintos como se advierte en la siguiente tabla.

\begin{tabular}{|c|c|c|c|c|}
\hline $\begin{array}{l}\text { Pago a contribuyente residente } \\
\text { en jurisdicción con REFIPRE }\end{array}$ & $\begin{array}{l}\text { Art. } 171 \\
\text { LISR }\end{array}$ & $\begin{array}{c}\text { Regla } \\
3.18 .24\end{array}$ & $\begin{array}{c}\text { 97/2013/ISR } \\
2013-2014\end{array}$ & $\begin{array}{c}\text { Arts. } 176 \text { y } 177 \\
\text { LISR }\end{array}$ \\
\hline Cualquier residente & $\begin{array}{l}\text { Retención } \\
40 \%\end{array}$ & & & \\
\hline $\begin{array}{l}\text { Residente en el extranjero que } \\
\text { no es parte relacionada }\end{array}$ & & $\begin{array}{l}\text { Sin re- } \\
\text { tención } \\
\text { del } 40 \%\end{array}$ & & \\
\hline $\begin{array}{l}\text { Parte relacionada pero el nacio- } \\
\text { nal NO recibe ingresos de ella }\end{array}$ & \multicolumn{4}{|c|}{ No aplica retención } \\
\hline $\begin{array}{l}\text { Parte relacionada y Sí recibe } \\
\text { ingresos de ella, sólo sí partici- } \\
\text { pa en la entidad o figura }\end{array}$ & & & $\begin{array}{l}\text { Retención } \\
\text { (ej. venta de } \\
\text { acciones) }\end{array}$ & $\begin{array}{c}\text { Anticipo del ingreso } \\
\text { ¿el mismo ingreso que } \\
\text { está pagando? }\end{array}$ \\
\hline
\end{tabular}

Tabla 1. Retenciones sobre pagos vinculados a REFIPRES en LISR y RMF 
¿Cómo repercute este entramado administrativo en la calificación de México?, nos parece obvia la respuesta, con ello se está propiciando que se utilicen compañías mexicanas (filiales de extranjeras) para realizar pagos a jurisdicciones con REFIPRES sin castigar esos flujos con la retención del 40\% y, en su momento, el criterio quizá propició la planeación con esquemas en donde no se actualizó la recepción de ingresos del residente en México desde la entidad o figura a la que se hizo el pago, con independencia del resto de los movimientos o flujos con los demás integrantes del grupo u otras partes relacionadas.

\section{MÉXICO, OFFSHORE PARA EXTRANJEROS}

En el apartado anterior analizamos la forma en que México regula o "desregula" las inversiones y pagos vinculados a REFIPRES, considerando que esos REFIPRES se encuentran en jurisdicciones allende la frontera mexicana. Ahora revisamos algunas reglas administrativas en las que parece que el país ofrece beneficios preferentes a los residentes en el extranjero que inviertan en el país en forma directa o a través de subsidiarias.

Encontramos reglas principalmente bursátiles, referidas a la ganancia obtenida por la enajenación de certificados o títulos exentas del impuesto, así como reglas relacionadas con pagos de intereses al extranjero exentos del impuesto. El ejemplo claro es la siguiente regla: 3.1.12. Ganancia en la enajenación de certificados bursátiles fiduciarios de un fideicomiso que exclusivamente esté invertido en FIBRAS.

También localizamos reglas que crean un régimen impositivo para diversos fideicomisos y otorgan la exención que está prevista en la LISR para ciertas operaciones. En este caso, lo relevante es que cuando la 
LISR otorga una exención, ha pasado por los filtros de rendición de cuentas y valoración financiera a que se refiere la Ley de Ingresos de la Federación y la Ley Federal de Presupuesto y Responsabilidad Hacendaria, pero cuando una regla replica un tratamiento legal a un nuevo esquema o fideicomiso, no supera los mencionados filtros. Ejemplo: 3.21.3.3. Tratamiento fiscal de los fideicomisos de inversión en energía e infraestructura.

Un tercer tipo de reglas quizá de beneficio para el país, son reglas que favorecen el pago de intereses por contribuir a fines económicos nacionales, pero que nuevamente no pasan por los filtros de control y rendición de cuentas y significan, sin embargo, una exención impositiva no prevista en la LISR. Ejemplo: 3.16.9. Intereses exentos del ISR, percibidos por extranjeros.

Otro tipo de reglas, son las que establecen bases impositivas distintas a las previstas legalmente, sin que se demuestre si la modificación a las bases tributarias puede generar, o no, un gasto fiscal para el Estado. En este grupo existen las siguientes reglas: 3.19.3. Cuenta de ingresos, dividendos o utilidades sujetas a REFIPRE; 3.2.8. Determinación de la ganancia o la pérdida por la enajenación de certificados de fideicomisos que repliquen índices bursátiles; 3.2.17. Mecánica para determinar la ganancia por la enajenación de acciones recibidas en préstamo; 3.2.19. Procedimiento para determinar el precio de los activos objeto de inversión de renta variable y 3.2.22. Ganancias en operaciones financieras derivadas de capital referidas a acciones o índices.

Una última categoría de reglas, son las que reducen el universo de contribuyentes a quienes se aplica una disposición legal. En este rubro se encuentra la regla 3.18.24. Retenciones en operaciones con partes relacionadas, previamente analizada. 


\section{CONCLUSIONES}

Después de analizar los conceptos básicos sobre los REFIRES y la RMF, concluimos que la oscuridad en la emisión y administración de las disposiciones administrativas, actualizan uno de los supuestos relevantes que se observan a nivel internacional para (des)calificar a un país como desleal en su tributación y, a nivel nacional, reflejan el incumplimiento al deber de rendir cuentas a cargo de la autoridad.

Asimismo, apreciamos que a partir de decisiones administrativas sí es posible mermar el ámbito de aplicación de una ley fiscal, ya sea reduciendo a los sujetos a quienes se dirige la ley o bien disminuyendo las obligaciones sustantivas. Esta extensión puede impactar en los recursos del Estado ya que se constituyen verdaderos "gastos fiscales" no analizados por el filtro de las finanzas públicas.

No obstante, cuando se valora a la RMF, tanto desde el punto de vista doctrinal como jurisdiccional, la litis sigue siendo resolver si es o no constitucional por violentar los principios de legalidad y reserva de ley. Así, es necesario modificar el punto de vista de análisis para obligar, tanto a las autoridades fiscales como al Poder Judicial, a revisar la RMF desde dos nuevas perspectivas: a) como posibilidad de incumplimiento de los parámetros para constituir un REFIPRE y, b) para obligar a las autoridades a rendir cuentas relacionadas con los ingresos públicos, ya que si esa RMF reduce la aplicación de la ley, necesariamente habrá repercusiones en los ingresos y gastos nacionales.

Concluimos además, que la falta de normatividad que precise la forma en que debe discutirse, aprobarse y valorarse una regla miscelánea, obedece a que desde la perspectiva legal, la autoridad recaudadora que las emite sólo tiene facultades para aplicar la legislación, de ahí que pu- 
diera considerarse innecesaria una normatividad que trascienda a dicha función. Sin embargo, en vista de lo que analizamos en este artículo, es evidente que a través de la RMF se hace mucho más que sólo aplicar la ley o facilitar su cumplimiento.

En otro orden de ideas, es importante mencionar que la falta de información oficial no permite conocer la corrección o lo inadecuado de lo que se legisla a través de tales disposiciones administrativas. En ese sentido, no podríamos opinar si lo que establece la RMF al limitar la aplicación de las normas de la LISR relacionados con los REFIPRES y reducir el ámbito subjetivo de aplicación o generar exenciones a residentes en el extranjero, pudiera ser o no acorde con algún criterio internacional o hasta de beneficio económico para el país y, nos parece que en eso también pierden las autoridades fiscales; es decir, la falta de transparencia respecto de sus objetivos impide una posible aceptación de sus actos.

En ese contexto, nuestra sugerencia específica es que se deben implementar mecanismos de evaluación pre y post facto de las reglas y criterios que componen a la RMF, que permitan conocer sus impactos jurídicos y económicos, como sí se exige tratándose de iniciativas de leyes fiscales. También sugerimos establecer a cargo de la emisora, la obligación expresa de rendir cuentas, en tanto que la RMF incide en los ingresos y gastos públicos, una vez que, "de hecho", dejó de ser el instrumento de asistencia referido en el CFF.

Finalmente, es importante reconocer que, si bien un régimen preferencial atrae inversiones, lo cierto es que la mejor garantía que puede ofrecer un país para la captación de capital es la certidumbre jurídica; rubro en el que aún falta mucho por hacer en México. 


\section{FUENTES}

\section{BIBLIOGRAFIA}

European Commission, Questions and answers on the EU list if no-cooperative tax jurisdicions, http://europa.eu/rapid/press-release_MEMO-19-1629_en.pdf.

European Parliament, Listing of tax haven by the EU, 2018, http://wereweeuroparl. europa.eu/thinktank/en/document.html?'reference $=E P R S \_B R I(2018) 621872$.

Instituto Nacional De Estadística Y Geografía, Sistema de Clasificación Industrial de América del Norte, México, SCLAN 2018, http://internet.contenidos.inegi.org.mx/ contenidos/Productos/prod_serv/contenidos/espanol/bvinegi/productos/nuevo_estruc/702825099695.pdf.

KaYne, Dionisio J., "Constitucionalidad y juridicidad de a resolución miscelánea fiscal”, en Nuevo consultorio fiscal, Año 15, No. 286, julio de 2001, México, UNAM, FCyA, 2001.

(OCDE) Organización para la Cooperación y el Desarrollo Económicos, Glossary of tax terms, http://wrere.oecd.org/ctp/glossaryoftaxterms.html.

—- Harmful Tax Competition: An Emerging Global Issue, París, OECD, 1998, http://dx.doi.org/10.1787/9789264162945-en.

— Plan de acción contra la erosión de la base imponible y el traslado de beneficios, París, OECD, 2014, http://dx.doi.org/10.1787/9789264207813-es.

- Combatir las prácticas fiscales perniciosas, teniendo en cuenta la transparencia y la sustancia. Acción 5. Informe final 2015, Paris, OCDE, 2016, http://dx.doi. org/10.1787/9789264267107-es.

—, Harmful Tax Practices - 2018 Progress Report en Preferential Regimes: Inclusive Framework on BEPS: Action 5, Paris, OCDE, 2019, http://dx.doi. org/10.1787/9789264311480-en. 
Pérez de Acha, Luis M., "Resolución miscelánea fiscal”, en Lex, difusión y análisis, 3르. época, año $\mathrm{V}$, junio 2002, número 84.

Pérez Góngora, J. Carlos, “Constitucionalidad de la miscelánea fiscal”, en Tribunal Federal de Justicia Fiscal y Administrativa a LXX años de la ley de justicia fiscal, II, México, TFJFA, 2006.

Ramírez FigueroA, Enrique, "Los regímenes fiscales preferentes”, en PÉREZ ROBLES, Arturo (coord.), Los convenios de doble imposición y su interrelación con las medidas para prevenir el abuso en su aplicación, México, Themis, 2011.

REsÉnDiz NúÑEz, Cuauhtémoc, "La resolución miscelánea en materia fiscal: una aproximación”, Lex, difusión y análisis, 3ª . época, año V, junio 2002, número 84, México, 2002.

Revilla Martínez, Eduardo, "Transparencia fiscal y acuerdos de intercambio de información tributaria”, en RÍOS GRANADOS, Gabriela (coord.), Derecho internacional tributario, México, Porrúa-UNAM, 2010.

Reyes Bustamente, Andrés, "La miscelánea fiscal y los principios de legalidad y seguridad jurídica”, en Consultorio fiscal, No. 483, octubre de 2009, México, UNAM, FCyA, 2009.

Ríos Granados, Gabriela, "Naturaleza jurídica de las reglas generales en materia tributaria”, en Documentos de trabajo del Instituto de Investigaciones furídicas, México, UNAM, IIJ, 2003.

Roa Jacobo, Juan Carlos, "Transparencia fiscal, residencia y acuerdos de intercambio de información tributaria”, en RÍOS GRANADOS, Gabriela (coord.), Derecho internacional tributario, México, Porrúa-UNAM, 2010.

Servicio de Administracion Tributaria, Oficio No. 600-04-078-2013-16549, http://omawreressat.gob.mx/informacion_fiscal/normatividad/Documentos/criterios_normativos_19122013.pdf.

— - Oficio No. 600-04-07-2014-87379, http://omawrere.sat.gob.mx/informacion_fiscal/normatividad/Documentos/criterios_normativos_4otrimestre2014.pdf. 
Suprema Corte de Justicia de la Nación, Controversia constitucional 117/2014, en http://werww2.scjn.gob.mx/jurídica/engroses/3/2014/9/3_175161_2453.doc.

Velázquez Meléndez, Vicente, "La resolución miscelánea fiscal ces legal su aplicación?, en Nuevo consultorio fiscal, No. 434, México, UNAM, FCyA.

\section{LEGISLACIÓN}

Código Fiscal de la Federación, Diario Oficial de la Federación, México, 31 de diciembre de 1981 y reformas al 25 de junio de 2018.

Constitución Política de los Estados Unidos Mexicanos, Diario Oficial de la $\mathrm{Fe}^{-}$ deración, México, 5 de febrero de 1917 y reformas al 6 de junio de 2019.

Ley de Ingresos de la Federación para el ejercicio fiscal de 2019, Diario Oficial de la Federación, México, 28 de diciembre de 2018.

Ley del Impuesto sobre la Renta, Diario Oficial de la Federación, México, 11 de diciembre de 2013 y reformas al 30 de noviembre de 2016.

Ley del Servicio de Administración Tributaria, Diario Oficial de la Federación, México, 15 de diciembre de 1995 y reformas al 4 de diciembre de 2008.

Ley Federal de Presupuesto y Responsabilidad Hacendaria, Diario Oficial de la Federación, México, 30 de marzo de 2006 y reformas al 30 de diciembre de 2015 .

Ley Orgánica de la Administración Pública Federal, Diario Oficial de la Federación, México, 29 de diciembre de 1976 y reformas al 14 de mayo de 2019.

Reglamento del Servicio de Administración Tributaria, Diario Oficial de la Federación, México, 24 de agosto de 2015.

Resolución Miscelánea Fiscal para 2005, 2006, 2007, 2008, 2009, 2010, 2011, 2012, 2013, 2014, 2015, 2016, 2017, 2018 y 2019, Diario Oficial de la Federación, México, 30 de mayo de 2005, 28 de abril de 2006, 25 de abril 
de 2007, 27 de mayo de 2008, 29 de abril de 2009, 11 de junio de 2010, 1 de julio de 2011, 28 de diciembre de 2011, 28 de diciembre de 2012, 30 de diciembre de 2013, 30 de diciembre de 2014, 23 de diciembre de 2015, 23 de diciembre de 2016, 22 de diciembre de 2017 y 29 de abril de 2019 , respectivamente. 